\title{
MIDAS
}

Museus e estudos interdisciplinares

$4 \mid 2014$

Varia e dossier temático: "Museus, utopia e urbanidade"

\section{Objetos mediadores em museus}

Mediation objects in museums

Inês Ferreira

\section{OpenEdition}

Journals

Edição electrónica

URL: http://journals.openedition.org/midas/676

DOI: $10.4000 /$ midas.676

ISSN: 2182-9543

Editora:

Alice Semedo, Paulo Simões Rodrigues, Pedro Casaleiro, Raquel Henriques da Silva, Ana Carvalho

Refêrencia eletrónica

Inês Ferreira, "Objetos mediadores em museus », MIDAS [Online], 4| 2014, posto online no dia 10 fevereiro 2015, consultado no dia 30 abril 2019. URL : http://journals.openedition.org/midas/676 ; DOI : 10.4000/midas.676

Este documento foi criado de forma automática no dia 30 Abril 2019

\section{(c) (i) (3) (2)}

Midas is licensed under a Creative Commons Attribution-NonCommercial-ShareAlike 3.0 International License 


\title{
Objetos mediadores em museus
}

\author{
Mediation objects in museums
}

Inês Ferreira

\section{NOTA DO EDITOR}

Artigo recebido a 31.03.2014

Aprovado para publicação a 21.10.2014

\section{Introdução}

1 No século XXI o aumento e a diversificação de meios de informação e de comunicação coloca à disposição das pessoas, a nível pessoal e profissional, mais oportunidades para participar, escolher e interagir de forma ativa, como o demonstram diversos estudos (Simon 2010). Neste contexto de mais e de diferentes oportunidades de participação, também os museus se abrem hoje à possibilidade do visitante participar, criar e partilhar.

2 Num museu, as exposições podem centrar-se na transmissão de informação - histórica, artística, social - e fazem-no, por vezes, a uma só voz, sem mostrar diversas perspetivas, conduzindo a uma apreensão passiva de conteúdos. Mas as exposições podem expor diferentes vozes - tabelas com diferentes perspetivas, visitas orientadas que apresentam diversos olhares, objetos mediadores que convidam à participação ativa dos visitantes na construção de conteúdos. O museu assume-se, neste caso, como espaço participativo e a introdução de objetos mediadores como forma de os tornar participativos. Essa inserção de objetos mediadores adiciona à exposição narrativas múltiplas, que «podem aumentar o espaço da exposição, criando realidades de media mistos híbridas» (Svabo 2010, 282) e níveis de narrativa novos.

3 A discussão proposta neste artigo parte da constatação de que existem hoje museus e instituições culturais mais tradicionais e outros mais interativos que, à partida, se 
poderiam considerar mais participativos. Serão os primeiros mais focados na transmissão de informação e os segundos na participação do visitante? Será que todos os museus têm de passar a ver o visitante como participante? o museu participativo tomará o lugar das instituições culturais mais tradicionais? Será que um museu tradicional pode ser mais participativo do que um museu interativo? Baseamo-nos na tese defendida por Simon (2010), de que o museu participativo não toma o lugar das instituições culturais tradicionais, não se lhe substitui, mas essas instituições culturais podem alargar-se à participação, ao manter a relevância para quem já as visita e aumentando a relevância para quem não as visita ainda e não se revê no seu discurso. Consideramos também que um museu interativo que envolva as mãos, mas não a mente, pode ser menos participativo que um museu com um discurso mais tradicional, mas que integre, por exemplo, diversos pontos de vista e leve o visitante a questionar-se. A questão que colocamos é se mesmo museus cujo discurso expositivo fale a uma só voz podem tornar-se participativos, através da introdução de objetos mediadores que questionem essa voz dominante, que introduzam outras perspetivas e convidem à participação biográfica, perspetivando-se como espaço participativo e colaborativo (Simon 2010), de cruzamento de vozes e perspetivas (Hooper-Greenhill 2007). Questionamos ainda se, para a visita ser criativa, é necessário o visitante entrar na experiência de forma pessoal. Partimos do fundamento construtivista de que se aprende melhor quando se envolve o eu de cada um no processo (Hein 1998). $O$ encontro do visitante com uma exposição é sempre pessoal, no entanto, quando uma exposição apresenta uma única perspetiva, o visitante é induzido a uma apreensão passiva de conteúdos, que dificulta a construção pessoal de significados (Rice e Yenawine 2002). Se todo o encontro visitante-exposição é pessoal, nem sempre acontece a personalização da visita, ou seja, nem sempre se trata de uma experiência de interioridade. Ora, se o envolvimento do visitante na visita, com a sua biografia, é relevante para que a visita seja criativa e participativa, é importante encontrar formas de fomentar a participação biográfica. Discutiremos se a introdução de objetos mediadores poderá ser uma forma de o fazer.

O artigo inicia com a revisão da literatura sobre museus participativos e objetos mediadores e discute, com base na análise da literatura e de exemplos emergentes, se os objetos mediadores podem tornar o museu mais participativo e criativo. Essa discussão pode influenciar as práticas dos museus, nomeadamente:

- evidenciando o potencial dos objetos mediadores para expandir a realidade duma exposição;

- apontando exemplos de visitas mediadas;

- sugerindo formas de intervir em exposições permanentes que apresentam uma só visão, abrindo-as a diferentes vozes e à participação e construção de conhecimento, através de objetos mediadores.

5 As questões teóricas analisadas sugerem a necessidade de trabalho de campo que experimente e avalie a introdução de objetos mediadores em contextos expositivos.

\section{Conceitos estruturais e metodologia}

6 Este artigo parte da análise de três conceitos estruturais no contexto do que aqui discutimos: museu participativo, experiência da visita e mediação em museus. Com base na revisão bibliográfica de cada conceito propomos uma abordagem articulada para criar o contexto teórico que fundamente o recurso a objetos mediadores em museus. A primeira questão que colocamos é se, mesmo em museus tradicionais nas coleções e 
exposições, a introdução de objetos mediadores poderá introduzir diferentes vozes e olhares. A segunda é se a participação pessoal facilita a que essa experiência seja criativa.

7 Cruzamos o contexto teórico apresentado com quatro casos de estudo. Os três primeiros tratam-se de grandes e prestigiados museus nos Estados Unidos que, apesar do peso da história e das coleções, abriram-se a diferentes vozes e olhares, de modos distintos. 0 Denver Art Museum, fundado em 1893, experimentou nos últimos 20 anos, de forma pioneira e continuada, a introdução de objetos mediadores no contexto da exposição. 0 Portland Museum of Art, fundado em 1882, destaca-se por introduzir objetos mediadores criados pelos próprios visitantes. O Sterling and Francine Clark Art Institute, construído em meados do século XX, salienta-se por recorrer a objetos mediadores mais tecnológicos. Estes museus americanos constituem exemplos de como coleções tradicionais se podem abrir à participação e a introdução de objetos mediadores de formas diversificadas, tornando-se mais participativas. Em contraponto apresentamos o Miraikan, no Japão, por se tratar de um museu completamente distinto. Se os primeiros três são museus com um peso de tradição forte que, partindo das coleções, souberam acolher e introduzir novas formas de mediação nas exposições, cada um de forma distinta, o Miraikan é um museu centrado na mediação em si e no potencial da tecnologia e não numa coleção. Pretendemos desta forma mostrar que, seja num museu com grande peso institucional e tradição, seja num museu altamente tecnológico e moderno, a abertura à participação e a introdução de objetos mediadores é um caminho possível, dependendo, essencialmente, do posicionamento do próprio museu.

Por fim, apresentamos as conclusões e sugestões para trabalho futuro, reforçando a ideia de que este estudo potencia posterior trabalho de campo em museus, com objetos mediadores.

O primeiro conceito que visitamos é o de museu participativo. A participação é muitas vezes associada aos conceitos de hands-on e interação, sobre os quais há posicionamentos distintos. Se alguns consideram que a interatividade é fundamental para envolver o visitante nas exposições, outros consideram que a interação pode envolver o visitante sem conduzir à aprendizagem (Caulton 1998). Consideramos que, mais do que defender um ou outro ponto de vista, o importante é que, em exposições hands-on, a interação leve ao envolvimento da mente, ao minds-on. Optamos por isso pelo conceito de participação, não tão associado à ideia de hands-on e implicando necessariamente o envolvimento da mente. Uma experiência é participativa se é «expressiva de qualquer forma, quer resulte ou não na geração de conteúdos» (Brown e Novak-Leonard 2011, 5). A expressão nasce do interior para fora e, nesse sentido, a experiência participativa exige um envolvimento do eu do visitante. Também Pierroux (2007) refere que na experiência da visita os visitantes se apropriam do significado que emerge do seu encontro com as exposições e que essa apropriação ${ }^{1}$ - implica um envolvimento pessoal, a que Bakhtin (1986, citado por Pierroux $2007,220)$ se refere como o «aspeto expressivo» dessa experiência. Kotler menciona que, num museu: «Encontrar significado pode ser uma experiência. Ponderar e discernir padrões em arte pode ser uma experiência. Ver-se envolvido num devaneio pode ser uma experiência. Sentir espanto e encantamento pode ser uma experiência» (Kotler 2003, 13). É este conceito de experiência, abrangente e integrando o sensorial e cognitivo, que adotamos.

Philip e Keil Kotler encontraram, na sua investigação, seis experiências distintas nos museus, que normalmente se sobrepõem: experiência de perceção estética, visual e sensorial; experiência social; experiência recreativa; experiência de aprendizagem; 
experiência de celebração da criatividade e dos feitos do homem; experiência de encantamento e grandiosidade (Kotler 2003).

11 O visitante/participante pode então participar na experiência da visita em diferentes dimensões. Mas pode também participar a diferentes níveis, mais ou menos ativos, mas todos participativos, desde que expressivos e envolvendo o eu. Um estudo promovido pela Wallace Foundation em 2004 (Brown 2004a) sugere cinco modos de participar nas artes, que adotamos: participação inventiva, com a mente, corpo e espírito, acontece quando a mediação convida a criar; participação interpretativa, adiciona valor ao objeto exposto e convida a interpretar; participação curatorial, quando a mediação convida a organizar e selecionar, por exemplo, participar na montagem duma exposição; participação observacional, quando um indivíduo seleciona ou comenta uma experiência artística; por fim, participação ambiental, envolve o contacto com objetos selecionados pelo indivíduo, à medida que se cruza com as obras (Brown 2004b, 12).

o museu participativo é, assim, convidativo a muitas formas de estar, de ver e de experimentar. É aberto à construção colaborativa, a diferentes formas de participar, à partilha de conteúdos, valorizando o contributo do indivíduo para a construção de significados. É neste contexto que podemos discutir como é que a experiência da visita pode ser criativa e pessoal (Ferreira 2013b) e o que é a mediação em museus para, posteriormente, analisarmos como é que os objetos mediadores fomentam que essa experiência mediada seja criativa e pessoal.

O segundo conceito que visitamos é o de experiência da visita. Existem duas posições distintas sobre a aprendizagem numa visita: se deve focar-se no ensino sobre arte ou história, por exemplo; ou se deve focar-se no desenvolvimento das capacidades críticas e criativas, no ensino através da arte e da história (Rice e Yenawine 2002). Defendemos que ambas as aprendizagens acontecem num museu, mas é a segunda que distingue a aprendizagem num museu e é sobre ela que nos focamos. A experiência de visitar e de participar numa exposição, de forma mais ativa ou reflexiva, pode ser sempre uma experiência criativa. Entendemos que uma experiência é criativa quando gera relações ou ideias novas, criando valor. $O$ pensamento imaginativo e criativo é responsável pela criação dessas relações e ideias novas. Quando o visitante/participante se relaciona com uma exposição, o pensamento imaginativo e criativo permite-lhe olhar por detrás das obras e dos objetos, ver ou imaginar novas relações e ideias, como refere Green: «(...) olhar por detrás das coisas que existem e perceber novas possibilidades de visão, novas extensões da consciência» (Green 1998, citado por Bedford 2004, 6).

É nesse processo de ver, pensando, e pensar, vendo, que o pensamento imaginativo e criativo vai atuando e possibilita a criação de novas relações, ideias e atitudes (Ferreira 2012). Para o pensamento imaginativo e criativo gerar criatividade é necessário conhecimento, motivação e pensamento crítico. O conhecimento novo resulta do encontro daquilo que o visitante/participante "carrega" consigo (conhecimento, experiência, memória, sensações) com aquilo que encontra no museu/exposição. Dessa sobreposição resulta uma rede de potenciais inter-relações. Quando o conhecimento do visitante/participante se cruza com o que encontra no museu, o pensamento imaginativo e criativo cria analogias, correlações de ideias, novas combinações que são mais complexas quanto mais complexo é o terreno de atuação.

15 A experiência criativa duma visita é pessoal, pois resulta da interceção de dois campos de conhecimento, sendo um deles o mundo interior do visitante/participante. A complexidade do conhecimento que o visitante/participante carrega consigo potencia, 
assim, uma visita mais criativa. Mas para que esta interceção aconteça, são necessários espaços inbetween, que permitam que o pensamento imaginativo e criativo atue.

Os espaços inbetween permitem ao visitante/participante andar por entre as unidades de conhecimento e criar relações entre elas (Latimer e Skeggs 2011, 54). Se o espaço/terreno de uma exposição é rico e complexo e o espaço interior de um visitante/participante é também rico e complexo, o potencial para uma visita criativa é grande. Mesmo nesse caso, de complexidade dos dois espaços, se não há interceções, não surgem novas relações e ideias, não se gera criatividade nem mudança. Isso pode acontecer por falta de tempo, de motivação ou de ferramentas que facilitem o uso do pensamento imaginativo e criativo. Por isso, não basta criar exposições com um alto nível de complexidade, é importante criar ferramentas que facilitem a exploração criativa dessas exposições e permitam ao visitante/participante andar pelos espaços inbetween e construir ligações, significados, conhecimento. Essas ferramentas podem materializar-se através de objetos mediadores. Mas o pensamento imaginativo e criativo não atua sozinho, exige a intervenção do pensamento crítico. O pensamento crítico tem função de filtragem, ao avaliar e selecionar, entre as múltiplas relações e ideias criadas pelo pensamento imaginativo e criativo, as que criam valor. Enquanto numa visita a uma exposição o pensamento imaginativo e criativo cria relações entre o que o visitante/participante carrega consigo e o que encontra, o pensamento crítico seleciona, avalia e sintetiza.

Num espaço expositivo algumas obras retêm o tempo e o olhar do visitante/participante, outras questionam, outras não o fazem parar. É o pensamento crítico que seleciona onde parar, o que focar, o que ver em detalhe (Ferreira 2013a). Quando, ao deixar o museu, revemos na mente as obras ou as ideias que deixaram eco em nós, fazemos a síntese da visita. De novo, recorremos ao pensamento crítico, que é uma ferramenta que personaliza a experiência (Vieira e Vieira 2001). Os espaços inbetween são, assim, espaços de criatividade, que permitem que o museu seja um espaço transformativo. Quando o visitante/participante sai da visita e o seu modo de ver e pensar se transformou, ele usou esse espaço inbetween como espaço de criatividade, de integração de conhecimentos e de criação de relações novas.

Para que a criatividade aconteça é importante mediar a relação exposição-visitante, potenciar a criação de relações. A mediação mais comum nos museus é com textos, visitas orientadas, monitores e atividades que, de alguma forma, facilitam a ligação visitante/ exposição. A introdução de objetos mediadores no espaço expositivo é uma estratégia para o conseguir. Qualquer agente mediador, de acordo com Kadobayashi et al. (1998), personaliza as exposições, de forma a alcançar os interesses da cada visitante, criando a possibilidade de reconstruir as exposições à medida de cada um. Ou seja, quando numa exposição existe um objeto mediador que desafia cada visitante a ver, a ler, a refletir, em diálogo com a sua memória, experiência e interesses, esse processo leva à reconstrução por cada indivíduo dos significados potenciados pela exposição. 


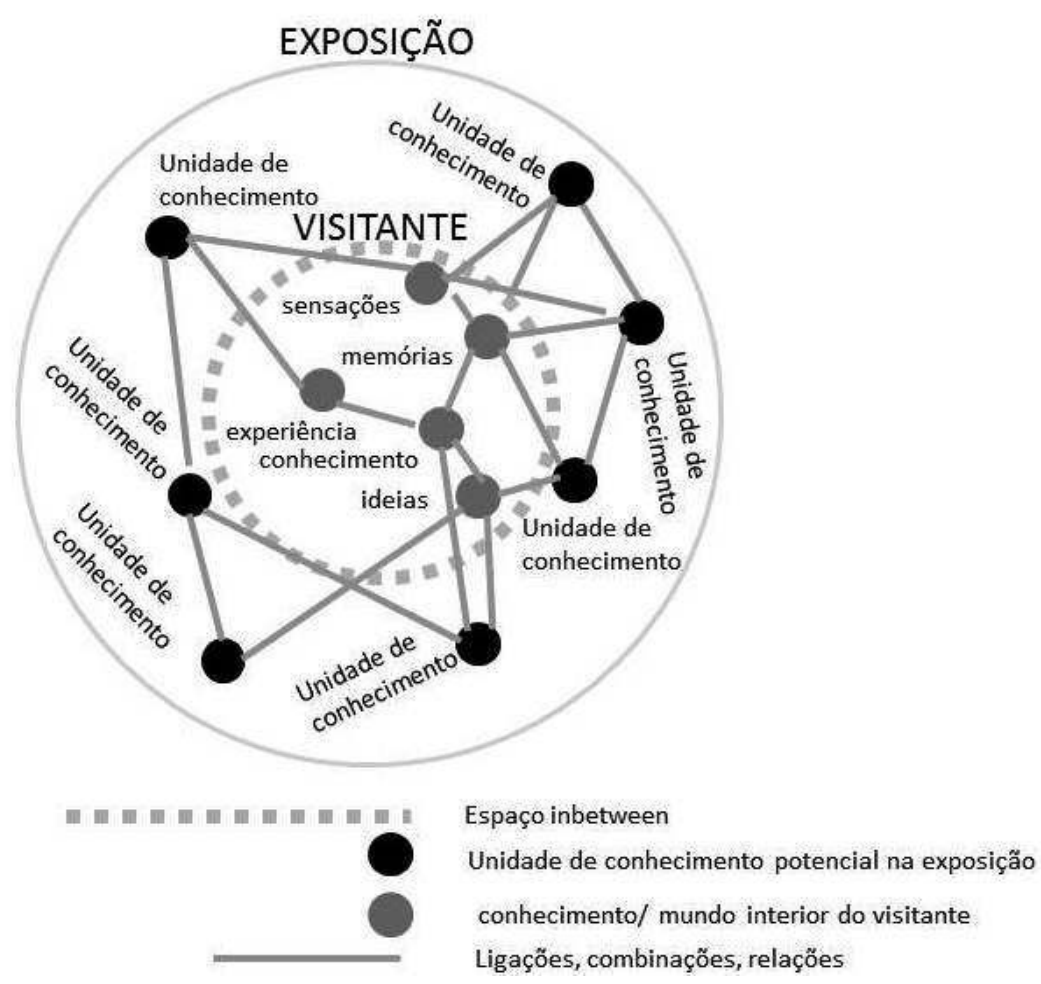

Fig. 1 - Esquema desenhado e proposto pela autora, que mostra o Espaço inbetween como zona de contacto/interceção entre o visitante e a exposição, espaço de criatividade, integração de conhecimento, e criação de relações novas.

19 O terceiro conceito que visitamos é o de mediação. Podemos pensar o museu como objeto mediador, entre o indivíduo e o mundo, assim como a exposição como objeto mediador entre o indivíduo e o museu. Mas é nos processos de mediação que facilitam o encontro visitante-artefacto que nos focamos. Alguns autores (Kadobayashi et al. 1998) referem-se aos agentes de mediação, responsáveis por essa aproximação. Pierroux (2007) refere os diversos instrumentos mediadores potencialmente presentes numa exposição - arquitetura do museu, conteúdos temáticos, práticas de olhar, conversações, tabelas, websites, blogues, catálogos - tudo o que medeia a relação visitante/participante - artefactos. Se alguns desses instrumentos são pensados para mediar a relação do visitante/participante com os artefactos, outros não são pensados com esse fim mas acabam por mediar indiretamente - arquitetura do museu, por exemplo.

Svabo (2010) refere-se a objetos portáteis, que não fazem parte duma exposição mas utilizam-se para mediar a relação visitante/participante-exposição. Podem ser trazidos pelo visitante/participante (bloco de notas, máquina fotográfica, por exemplo) ou disponibilizados pelo museu (livro de comentários, desdobrável, mesa de atividades). Estes objetos portáteis adicionam múltiplas narrativas e ampliam o espaço da exposição ( ibidem).

21 Neste artigo, quando falamos de objetos mediadores, referimo-nos aos objetos trazidos pelo visitante/participante ou disponibilizados pelo museu que não fazem parte da exposição, mas medeiam a relação do visitante/participante com os artefactos ou temáticas. Consideramos a mediação no sentido de Latour, em que mediar é associar e ligar, mas também transformar (Latour 1991). O mediador não é um mero intermediário, é um agente transformador. 
Poderemos questionar a mediação numa exposição. Referimos anteriormente que, para criar conhecimento não basta haver complexidade duma exposição e conhecimento prévio do visitante/participante, é preciso que nos espaços inbetween se criem relações e interceções. É nesses espaços que se pode questionar a mediação - objetos mediadores que facilitem, provoquem ou incentivem a integração de conhecimentos, de novas relações e de criatividade.

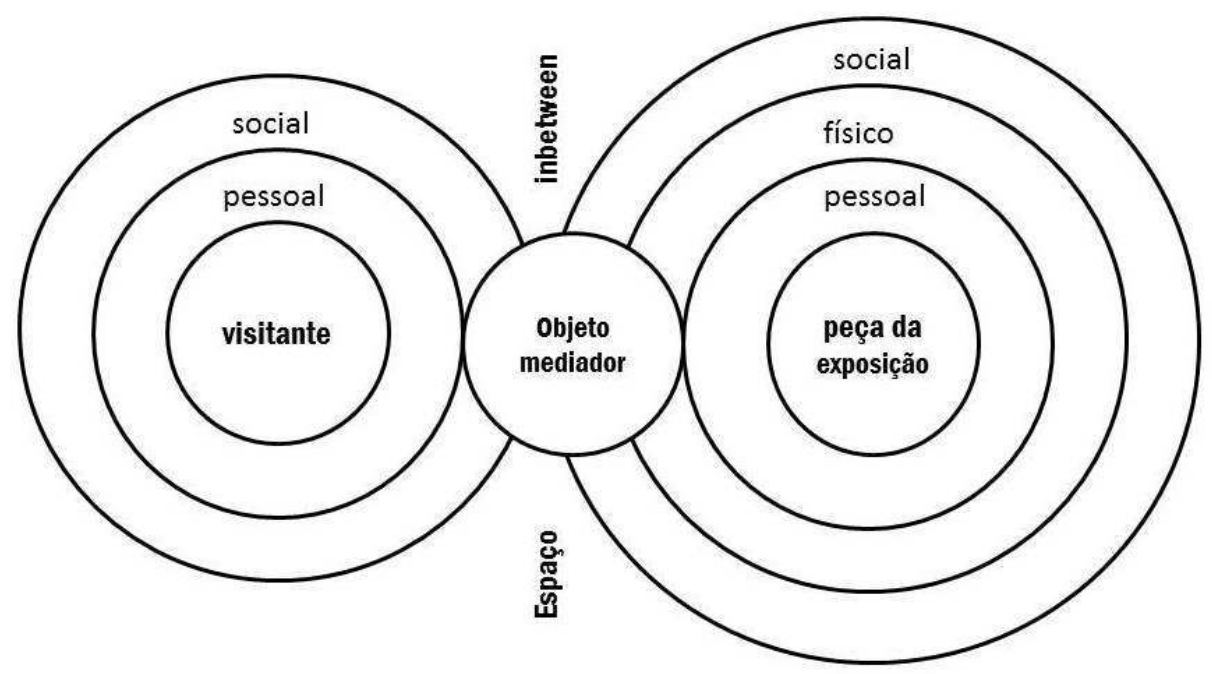

Fig. 2 - Esquema de Walker adaptado pela autora. Walker propõe um modelo de mediação - TrACE, por sua vez, baseado no modelo da experiência no museu de Falk e Dierking (1992) O objeto mediador faz a ligação entre o contexto pessoal e social do visitante e o contexto pessoal, físico e social das peças de coleção. A autora acrescenta a este esquema o espaço inbetween, como espaço potencial de transformação e construção de significados.

Felton e Kuhn referem que, numa exposição: «(...) os visitantes precisam de orientação para saber o que procurar, o que significa, e como avaliar e relacionar múltiplas fontes de conhecimento» (Felton e Kuhn 2007, 109).

Este é, efetivamente, o grande argumento em favor do recurso a objetos mediadores - o visitante precisa de orientação para usar ferramentas do pensamento crítico. O visitante/ participante é construtor do seu próprio conhecimento, num processo pessoal em que o museu passa a ser facilitador e não "dono" do processo. Como refere Freedman:

(...) os museus precisam de deixar de ser fornecedores de informação para passarem a ser facilitadores, fornecendo ferramentas para os visitantes poderem explorar as suas próprias ideias e chegar às suas próprias conclusões. (Freedman 2000, 299)

O aumento de possibilidades que as tecnologias trouxeram nos últimos anos complexificou este processo. A quantidade de informação, a possibilidade de escolha e participação colaborativa aumentou a importância de selecionar e tomar decisões, por parte do visitante/participante. Como acrescenta Freedman «(...) o aumentar do acesso às tecnologias, como à internet, colocou o poder da comunicação, da recolha de informações e da análise, nas mãos dos indivíduos do mundo» (ibidem).

26 A verdade é que a transformação potenciada pelas tecnologias tem duas faces indissociáveis. Por um lado, o aumento de possibilidades de escolha e de participação aumenta a liberdade. Por outro lado, a imensidão de informação e o ritmo a que surge nova informação dificulta a transformação dessa informação de forma crítica e analítica e o indivíduo precisa de ferramentas do pensamento crítico para o conseguir. 

os diversos utilizadores acedam a essa informação e conhecimento (Kelly 2006). É o processo de personalização, referido por Kadobayashi et al. (1998). Num tempo em que as tecnologias colocaram nas mãos do visitante/participante novos poderes ${ }^{2}$, como o de escolher e participar colaborativamente, torna-se importante a mediação pois, como refere Cochrane: «(...) apesar de ter mais informação ao nosso alcance do que qualquer geração antes, há pouca evidência de que a nossa capacidade de tomar boas decisões, oportunas, melhorou» (Cochrane 2003, 1, citado por Kelly 2006). Por isso, Kelly menciona que: «(...) os indivíduos precisam de ajuda para negociar e utilizar as informações na tomada de decisões» (Kelly 2006, 1).

É neste contexto que se defende o recurso a objetos mediadores para promover o uso das capacidades críticas e criativas. Os objetos mediadores orientam o visitante/participante na sua relação com uma exposição, de modo a usar o pensamento crítico e criativo nos processos de seleção, de análise, de imaginação, de avaliação e de decisão. Neste artigo analisamos o papel dos objetos mediadores enquanto promotores do pensamento crítico e criativo no espaço inbetween, num processo pessoal e biográfico.

\section{Objetos mediadores, facilitadores do envolvimento pessoal/biográfico}

Visitados os conceitos basilares deste artigo, discutiremos como é que os objetos mediadores facilitam o envolvimento pessoal. Um objeto mediador medeia a relação do visitante/participante com a exposição e facilita a integração do conhecimento, patente na exposição e trazido pelo visitante/participante. Cada objeto propõe, segundo Svabo (2010) um modo de visita distinto e forma um ponto de intercâmbio entre o visitante e a exposição. $O$ visitante traz para este encontro o mundo exterior e interior e o museu traz outros mundos e saberes (ibidem). Svabo propõe o termo "modos de visita mediados" para este mundo novo, em que cada objeto propõe uma visita personalizada. Para Svabo, o visitante recria a exposição, quando se relaciona com ela mediado por um objeto mediador. A personalização da visita, potenciada pelos objetos mediadores, dá-se a vários níveis. Por um lado, cada objeto mediador propõe um modo de visita-distinto. Na mesma exposição, diversos objetos mediadores podem multiplicar os modos de visita mediados possíveis. Por outro lado, cada visitante, ao apropriar-se do objeto mediador para cruzar a exposição com a sua história personaliza a exposição.

MIDAS, 4 | 2014 


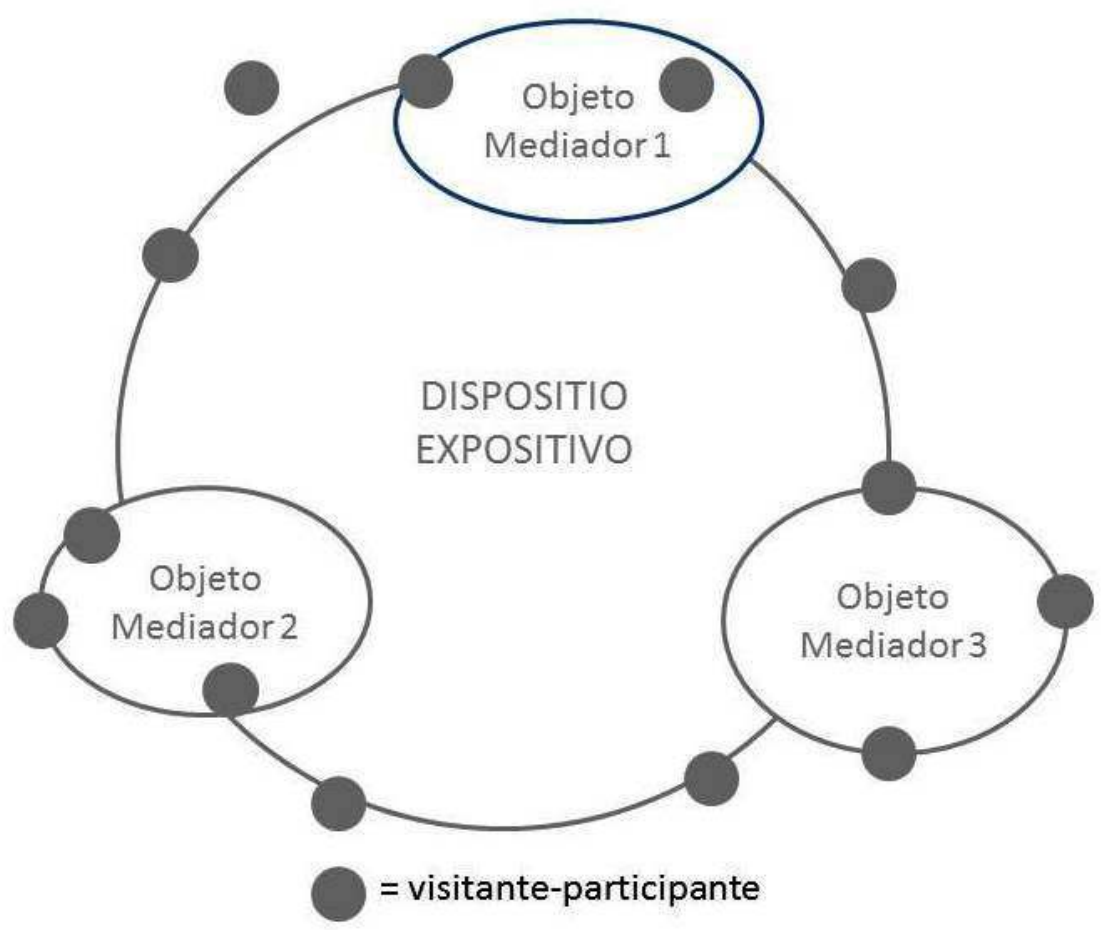

Fig. 3 - Esquema proposto pela autora para explicar a "Realidade Aumentada" em torno de um dispositivo expositivo - inspirado no conceito de modos de visita mediada de Svabo (2010). O objeto mediador cria múltiplos modos de visita e cada visitante personaliza a forma de usar os objetos mediadores, aumentando o espaço da exposição.

Como é que esses objetos mediadores potenciam o envolvimento pessoal do visitante/ participante? Um modo de o fazer é recorrer a estratégias criativas de procura, sugeridas por Heerwagen, que partem de onde se está e do que se conhece para ir à procura de "outro lugar". A aplicação destas estratégias aos objetos mediadores implica que estes incentivem o visitante a partir do que é, sabe e conhece, para ir em busca de "outro lugar", que surgirá do cruzamento entre dois mundos - o do visitante/participante e o da exposição. Isto implica assumir que o caminho que cada um faz, num museu, é único e pessoal. Esse "outro lugar" é o espaço inbetween, de interceção do conhecimento do visitante/participante com o potenciado pela exposição. As estratégias de procura permitem criar relações entre os dois campos de conhecimento, partindo do eu para a relação. Trata-se, assim, de facilitar que o visitante/participante se encontre a si mesmo numa exposição.

31 Aplica-se assim o conceito de mediação de Latour, segundo o qual olhar para objetos como mediadores implica considerar que eles são transformadores (Latour 1991). Para Latour, mediação implica associação, transformação, invenção. 0 mediador transforma o mediado. Dessa forma, os objetos mediadores não são meros transmissores de informação, são agentes de transformação.

Quando, perante um artefacto, o visitante/participante é "bombardeado" com informação sobre o mesmo - autor, data, contextos - através de tabelas, audioguias, visitas, num discurso centrado na transmissão de informação, será que o visitante/participante cria uma relação pessoal com o que vê? A informação poderá bloquear a criatividade, levando a uma apreensão dos conteúdos pouco crítica? 

"informação em torno do artefacto" - ensina um processo de receção passiva e não de observação ativa. Quando isso acontece o visitante/participante fica com a impressão de que precisa de muita informação para se relacionar com as obras e isso impede-o de observar e pensar por si. Se, pelo contrário, o visitante/participante for desafiado, num primeiro momento, a situar-se perante a obra, observá-la e questionar-se, quando receber informação conseguirá facilmente relacionar-se de forma pessoal e crítica, ao construir e integrar conhecimento novo. Sugerimos que o recurso às estratégias criativas de procura possa criar maneiras do visitante/participante se relacionar de forma pessoal com o contexto da exposição e apontamos exemplos de como alguns museus o procuram fazer. múltiplas formas de desafiar o visitante a partir de si e da sua experiência para a relação com as exposições. ${ }^{4}$ Este museu tem integrado diversos objetos mediadores, potenciando uma participação colaborativa do visitante/participante. Se alguns desses objetos são mais tecnológicos e exigem meios consideráveis, outros são de uma grande simplicidade. É o caso dos diários partilhados, no contexto expositivo deste museu, que incentivam o visitante/participante a partir de si na relação com a exposição (Fischer e Levinson 2010). Alguns diários desafiam o visitante a contar as suas histórias - "Conte-nos a sua história sobre..." -, recolhendo relatos em torno de um tema presente na exposição. Ao aproximar a história de cada um às histórias e temáticas da exposição, estes diários envolvem a biografia do visitante na exposição e aproximam cada visitante dos outros e das suas histórias - é uma participação anónima, mas pessoal. Outros diários partilhados sugerem que o visitante escreva a sua opinião sobre determinado assunto ou obra, que faça a sua apreciação pessoal, propondo uma participação interpretativa. Ao fazê-lo, o visitante/ participante situa-se perante a obra, observa-a e reflete de forma a que, quando receber informação em torno desse artefacto, ter-se-á já posicionado de forma pessoal e, por isso, crítica e conseguirá relacionar o que viu e refletiu com aquilo que vier a conhecer. Outros diários, ainda, desafiam o visitante/participante a criar um poema, no contexto de determinada temática ou artefacto, propiciando uma participação inventiva.

a mediação pode ser feita por objetos mediadores mais tecnológicos e complexos. 0 Sterling and Francine Clark Art Institute dispõe desde há alguns anos dum espaço expositivo - o Clark Remix - onde organiza exposições integrando pinturas, esculturas e objetos decorativos da coleção permanente (Brummett 2012, 23-24) organizados de forma surpreendente e distante da tradicional organização por região ou período. Aproximando artefactos e obras de muitas culturas e tempos, este espaço providencia um novo contexto para o visitante/participante se relacionar com os objetos. A mediar a relação do visitante/participante com estas exposições existem dois programas interativos, o uCURATE e o uEXPLORE. O uEXPLORE fornece informação detalhada sobre os objetos em exposição e o uCURATE, convida o visitante/participante a selecionar obras expostas e a criar a sua própria exposição virtual numa representação tridimensional de uma sala do museu. Nesta interação cada visitante/participante procura o que lhe interessa e relaciona com a sua vida, entrando numa experiência de participação curatorial.

Mas os objetos mediadores podem ser trazidos pelos visitantes. O Portland Museum of Art desenvolveu um projeto - Histórias de Objetos - que convidava os visitantes a selecionarem um objeto pessoal com significado para si, trazê-lo ao museu e partilhar uma história sobre ele com os visitantes e comunidade (Brummett 2012, 32-33). Essas histórias registadas em vídeo foram depois publicadas numa galeria online. $\mathrm{O}$ projeto integrava 
também uma exposição de objetos selecionados acompanhados das histórias associadas a cada um. Neste caso, a mediação entre objetos das coleções e os visitantes era feita por objetos pessoais de outros visitantes. Esta mediação potenciaa um envolvimento sensorial e afetivo.

Por fim, existem hoje objetos mediadores altamente tecnológicos, entre os quais destacamos um, no Miraikan - National Museum of Emerging Science and Innovation (Japão) - denominado GeoPallete. Este museu expõe uma enorme recriação em alta resolução de um globo gigante - o Tsunagari - que retrata a terra e é acompanhado por vários objetos mediadores. Um deles, a GeoPallete, desafia o visitante/participante a "sentir, a explorar e a criar o seu próprio mundo". Trata-se de um serviço online que permite desenhar um mapa-mundo original baseado nos dados sobre os países e as regiões que o sistema comporta, permitindo que cada um desenhe o seu mapa personalizado, e possa partilhá-lo. ${ }^{5}$ Este tipo de participação mediada desafia o visitante a entrar na experiência de forma pessoal.

Os objetos mediadores podem exigir recursos reduzidos - os diários implicam simplesmente papel e caneta - ou enormes recursos financeiros e tecnológicos - o Geopallete é exemplo. 0 importante na introdução de objetos mediadores é permitir que cada um entre na exposição de forma pessoal. Considerando que existem objetos mediadores que não exigem praticamente recursos, é possível introduzi-los em qualquer exposição, em museus grandes ou pequenos, de qualquer tipologia, alargando os níveis de relação possíveis e a realidade de cada exposição. É ainda relevante perceber que em museus tradicionais, como os três primeiros referidos, a introdução de objetos mediadores é uma porta aberta para se tornarem participativos. Se a nível de exposição e tipologia de museu os três primeiros museus estão num polo oposto ao quarto (até a nível geográfico procuramos simbolicamente essa polarização), a nível conceitual há algo que os aproxima: o recurso a objetos mediadores como forma de aproximar o visitante/ participante aos conteúdos e potenciar uma experiência criativa e pessoal. $O$ relevante na introdução de objetos mediadores é perceber que é necessário envolver o eu de cada um para que a experiência seja pessoal e criativa.

\section{Conclusão}

39 A introdução de objetos mediadores, mesmo em exposições tradicionais, permite abri-las a novas perspetivas e incentivar a participação ativa. Os objetos mediadores potenciam múltiplos modos de visita, a partir de uma mesma exposição, que se podem sobrepor e intercetar, aumentando a realidade da exposição e a possibilidade da visita ser biográfica e criativa. Eles personalizam a visita contribuindo para adaptar a exposição à medida de cada um. Podemos concluir que é possível alargar o espaço duma exposição e personalizar a visita com objetos mediadores.

Poderemos, no entanto, questionar-nos sobre os limites dos objetos mediadores - se na relação com os artefactos expostos se podem tornar preponderantes, autossuficientes ou, eles próprios, objetos de coleção. Essa é uma linha de investigação que pode dar sequência a este estudo.

41 É fundamental que os objetos mediadores proponham modos de ver e de se relacionar, mas que não os imponham; que abram perspetivas e promovam o pensamento divergente e que integrem pontos de relacionamento com o eu. 

muitas vezes, o único objeto mediador que encontramos nos museus. Dão-nos informação histórica e artística sobre os objetos, mas não propõe modos de ver e de relacionar, muito menos propõe perspetivas diversas e pontos de relacionamento com o eu de cada um. Uma linha de investigação interessante seria partir da análise dos objetos textuais existentes em alguns museus e avaliar o seu potencial criativo. Outra linha de investigação importante seria desenvolver formas de, com base na avaliação desses objetos mediadores, transformá-los em mediadores mais criativos. Uma terceira linha de investigação seria propor e experimentar outras tipologias de objetos mediadores nesses contextos em que só existem objetos mediadores textuais.

páticas existentes, mas não os usar como receitas, pois a introdução de objetos mediadores tem sempre de ser adaptada à identidade de cada museu.

O campo de investigação aqui exposto, em torno dos objetos mediadores em museus, tem potencial para contribuir para uma maior aproximação dos museus aos visitantes no século XXI e tornar os museus espaços participativos.

\section{BIBLIOGRAFIA}

Bedford, Leslie. 2004. "Working in the Subjunctive Mood: Imagination and Museums." Curator: The Museum Journal 47 (1): 5-11.

Brown, Alan S. 2004a. The Values Study: Rediscovering the Meaning and Value of Arts Participation. Fairfield: Alan S. Brown \& Associates LLC.

Brown, Alan. S., and Associates, LLC. 2004b. The Values Study: Rediscovering the Meaning and Value of Arts Participation. Fairfield: Alan S. Brown \& Associates LLC.

Brown, Alan S., e Jennifer L. Novak-Leonard. 2011. Getting in on the Act: How Arts Groups are Creating Opportunities for Ative Participation. [San Francisco]: The James Irvine Foundation.

Brummett, Meghan E. 2012. "Colaborative Creativity: Creating Participatory Experiences in Art Museums." MA thesis, University of Washington.

Caulton, Tim. 1998. Hands-on Exhibitions: Managing Interactive Museums and Science Centres. London e New York: Routledge.

Falk, John H., e Lynn D. Dierking. 1992. The Museum Experience. Washington D. C.: Whalesback Books.

Felton, Mark, e Deanna Kuhn. 2007. "How do I Know? The Epistemological Roots of Critical Thinking." Journal of Museum Education 32 (2): 101-110.

Ferreira, Inês. 2012. "Museums in the Twenty First Century: The Importance of Critical Thinking and Creative Thinking." The Transformative Museum - PhD Course Papers. http:// www.dreamconference.dk/wp-content/uploads/2012/05/Ferreira.pdf. 
Ferreira, Inês. 2013a. "Museus de Arte e Desenvolvimento do Pensamento Crítico e Criativo.” Comunicação apresentada no II Encontro Internacional sobre Educação Artística, i2ADS - Instituto de Investigação em Arte, Porto, 2, 3, 4 de abril de 2012. http://eiea.identidades.eu/pt-pt/content/ museus-de-arte-e-desenvolvimento-do-pensamento-critico-e-criativo.

Ferreira, Inês. 2013b. “Museus e Criatividade.” Revista Vox Musei: Arte e Património 1 (2): 200-214.

Fischer, Daryl, e Lisa Levinson. 2010. "Redefining Successful Interpretation in Art Museums." Curator: The Museum Journal 53: 299-323.

Freedman, Gordon. 2000. "The Changing Nature of Museums." Curator: The Museum Journal 43 (4): 295-306.

Heerwagen, Judith H. 2006. “Creativity”. http://www.au.af.mil/au/awc/awcgate/doe/ benchmark/ch15.pdf.

Hein, George. 1998. Learning in the Museum. London e New York: Routledge.

Hooper-Greenhill, Eilean. 2007. "Interpretative Communities, Strategies and Repertoires." In Museums and Their Communities, editado por Sheila Watson, 76-94. London e New York: Routledge.

Kadobayashi, R., et al. 1998. "Evaluation of Mediating Agents that Personalize Museum Exhibitions." Ninth International Workshop on Database and Expert Systems Applications (DEXA 1998), Austria, Vienna, 1998, agosto 26-28.

Kelly, Lynda. 2006. "Museums as Sources of Information and Learning: the Decision Making Process." Open Museum Journal (Contest and Contemporary Society: Redefining Museums in the 21 st Century) 8: s/p. http://australianmuseum.net.au/Uploads/Documents/10049/LJKelly-OMJ paper.pdf

Kotler, Neil. 2003. Creativity and Interactivity: New Ways to Experience, Market and Manage Museums. Melbourne: Kenneth Myer Lecture: Deakin University.

Latimer, Joanna, e Beverley Skeggs. 2011. "The Politics of Imagination: Keeping Open and Critical.

"The Sociological Review 59 (3): 393-410.

Latour, Bruno. 1991. “Technology is Society Made Durable.” In A Sociology of Monsters: Essays on Power, Technology, and Domination, editado por John Law, 103-131. London: Routledge.

Pierroux, Palmyre. 2007. "Museology and the Problem of Interiority." In Museum Landscapes: Zoning in on a Complex Cultural Field, editado por Peter Aronson, 217-223. Linkoping: Linkoping University Electronic Press.

Rice, Danielle, e Philip Yenawine. 2002. "A Conversation on Object-Centered Learning in Art Museums." Curator: The Museum Journal 45 (4): 289-301.

Simon, Nina. 2010. The Participatory Museum. Santa Cruz: Museum 2.0. http:// www.participatorymuseum.org/.

Svabo, Connie. 2010. "Portable Objects at the Museum." PhD thesis, Center for Experience Research, Roskilde University.

Vieira, Celina Tenreiro, e Rui Marques Vieira. 2001. Promover o Pensamento Crítico dos Alunos: Propostas Concretas para a Sala de Aula. Porto: Porto Editora.

Walker, Kevin. 2010. "Designing for Meaning Making in Museums: Visitor-Constructed Trails Using Mobile Digital Technologies.” PhD unpublished thesis, Institute of Education, University of London. 


\section{NOTAS}

1. Apropriação no sentido de "fazer algo seu", segundo Wertsch $(2002,120$, citado por Pierroux 2007).

2. Teoricamente as tecnologias colocam poder nas mãos do visitante. Poderemos, no entanto, questionar se será um poder condicionado pelos decisores do museu. Podemos ainda questionar se esse poder por si tem valor ou se ele necessita de ferramentas do pensamento crítico para se constituir como valor.

3. Factos e opiniões que não estão presentes visualmente na obra ou artefacto, como, por exemplo, a informação sobre data de criação, como foi feito, onde, etc.

4. Ver mais em http://www.denverartmuseum.org/about/research-reports.

5. Ver mais em http://www.miraikan.jst.go.jp/.

\section{RESUMOS}

Um museu participativo incentiva a que a experiência da visita seja criativa e pessoal. Facilita a participação biográfica do visitante - com a sua experiência, conhecimento e interesses. Muitas exposições, porém, não promovem esse envolvimento pessoal. Neste artigo apresentamos uma revisão da literatura que indicia que a mediação com objetos mediadores facilita o envolvimento pessoal, a construção de conhecimento e a criatividade. o problema teórico que colocamos é se os museus mais tradicionais se podem abrir à participação e, neste contexto, o nosso objetivo é perceber que papel podem ter os objetos mediadores nesse processo. Discutimos o recurso a objetos mediadores como forma de adicionar múltiplos níveis de relação e modos de ver, potencial que consideramos subaproveitado em muitos museus. Começamos por apresentar o museu como espaço potencialmente participativo, que convida a um envolvimento ativo e crítico - ativo, porque o visitante é desafiado a fazer coisas; crítico, porque é estimulado a pensar, optar, discutir e refletir. Discutimos depois diferentes formas de usar objetos mediadores para incentivar o visitante a um envolvimento com os artefactos, recorrendo à memória, experiência, conhecimento e sentimentos. A participação biográfica potencia o cruzamento entre o mundo interior do visitante e os artefactos e conteúdos do museu. Esse espaço de cruzamento - inbetween - é o espaço da construção de conhecimento. Apresentamos diversas formas de um museu, mesmo não sendo interativo, se tornar mais criativo e participativo, o que pode contribuir para uma mudança nas práticas dos museus, nomeadamente na montagem e remodelação de exposições permanentes.

A participatory museum encourages visitors to approach their visit as a creative and personal experience. It enables each visitor to contribute with all of his or her experience, knowledge, and interests. Many exhibitions, however, do not promote this personal involvement. This paper presents a review of literature that suggests that mediation, particularly mediation objects, facilitate personal involvement, the construction of knowledge, and creativity. The theoretical problem is if more traditional museums can be open to participation and, in this context, our aim is to understand the role of mediation objects in this process. We discuss the use of mediation objects as a manner of adding multiple levels of relationship and ways of seeing, a potential that 
we consider as being underexploited in many museums. The article begins by presenting the museum as a participatory space that invites to an active and critical engagement - active, because the visitor is challenged to 'do' and not merely to 'look'; critical because he/she is stimulated to think, choose, discuss and reflect. We then present different methods of using mediation objects to encourage visitors to engage with artefacts, using his/her memory, experience, knowledge and feelings. Biographical participation enhances the interaction between the inner world of the visitor and the artefacts and contents of the museum. This space in-between is the space of knowledge construction. Different ways of making a museum become a more creative and participatory place are presented, even if it is not an interactive museum, and the discussion may contribute to change practices, namely to rethink permanent exhibitions.

\section{ÍNDICE}

Keywords: participation, mediation objects, creativity, museum

Palavras-chave: objetos mediadores, criatividade, participação, museu

\section{AUTOR}

\section{INÊS FERREIRA}

Licenciada em Artes Plásticas pela Faculdade de Belas Artes da Universidade do Porto, tem mestrado em Artes pela City University (Londres) e é doutoranda em Museologia na Faculdade Letras da Universidade do Porto, com o tema de investigação Museus e Criatividade. Trabalha na Câmara Municipal do Porto há dez anos e aí coordenou vários projetos culturais relacionados com educação e museus. Trabalhou em diversos museus no Porto e é coautora de materiais de apoio ao visitante. Atualmente é bolseira da Fundação para a Ciência e a Tecnologia. inesspratleyferreira@gmail.com 